\title{
P05.70. Polypharmacy, interactions and collaborative care in the middle-aged and beyond
}

\author{
M Stargrove ${ }^{*}$, L Stargrove \\ From International Research Congress on Integrative Medicine and Health 2012 \\ Portland, Oregon, USA. 15-18 May 2012
}

\section{Purpose}

The popular perception of herb-drug and drug-nutrient interactions is that they are unintended and problematic. Actually, purposeful coadministration of therapeutic agents within a clinical strategy represents a valuable approach to complex and evolving patient-centered care. As individuals age, they are more likely to be prescribed pharmaceutical medications: many also take herbs and nutrients, which may interact. The occurrence of polypharmacy may be orchestrated or unsupervised, beneficial or risky, depending upon the individual patient's physiology, health status and medical condition(s) and the communication and collaboration among the involved healthcare providers.

\section{Methods}

A literature review was conducted using the following keywords: polypharmacy, herb-drug interactions, nutrientdrug interactions, safety, herbs, vitamins, minerals, amino acids, essential fatty acids, physiologics, nutraceuticals, nutritional supplements, adverse drug events, druginduced nutrient depletion, integrative healthcare delivery, trans-disciplinary models, collaborative care, multidisciplinary care, therapeutic strategies, patient self-care, patient-centered medicine, aging, middle-aged, elderly.

\section{Results}

The challenges of multidisciplinary care involving diverse philosophical and clinical traditions bring forth the opportunity and necessity of formulating new models of proactive polypharmacy focused on patient safety, therapeutic efficacy and evidence-informed clinical-decision making. Patient demographics of medication, herb

Oregon College of Oriental Medicine, Portland USA and nutrient usage, adverse drug event occurrence, and typical risk patterns are reviewed. Cardiovascular, degenerative bone and mind/mood conditions illustrate specific areas of concern.

\section{Conclusion}

Within the standard literature of pharmacy practice, several clinical management tools have been developed for eliciting, assessing, and managing multiple prescribed and over the counter drugs. By extending the tools for coordinating polypharmacy to encompass the full range of therapeutic agents, whether pharmaceutical, nutrient or botanical, clinicians can formulate and implement a patient-centered model of safe and effective polypharmacy.

Published: 12 June 2012

\section{doi:10.1186/1472-6882-12-S1-P430}

Cite this article as: Stargrove and Stargrove: P05.70. Polypharmacy, interactions and collaborative care in the middle-aged and beyond. BMC Complementary and

Alternative Medicine 2012 12(Suppl 1):P430.

Submit your next manuscript to BioMed Central and take full advantage of:

- Convenient online submission

- Thorough peer review

- No space constraints or color figure charges

- Immediate publication on acceptance

- Inclusion in PubMed, CAS, Scopus and Google Scholar

- Research which is freely available for redistribution

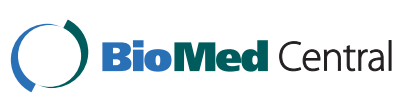

(c) 2012 Stargrove and Stargrove; licensee BioMed Central Ltd. This is an Open Access article distributed under the terms of the Creative Commons Attribution License (http://creativecommons.org/licenses/by/2.0), which permits unrestricted use, distribution, and reproduction in any medium, provided the original work is properly cited. 